\title{
Phytochemical Screening and Evaluation of Antibacterial Activity of Ruta graveolens L. - A Medicinal Plant Grown around Mekelle, Tigray, Ethiopia
}

Teklit Gebregiorgis Amabye* and Tanveer Mahamadail Shalkh

Department of Chemistry, College of Natural and Computational Science, Mekelle University, Mekelle, Tigray, Ethiopia

\begin{abstract}
Ruta graveolens $\mathrm{L}$. is aromatic shrub belongs to family rutaceae. It is ornamental and medicinal plant used in the treatment of inflammation, ulcer, hypotension, reproductive disorders, menstrual problems, parasitic infection, wounds and injuries. The plant extracts showed good antibacterial and antifungal properties. Fresh leaves were collected and leaves were shade dried and powdered. 5 grams of powder extracted with $25 \mathrm{ml}$ different solvents, ethanol, methanol, chloroform and distilled water. Crude solutions were further diluted to $1 / 10^{\text {th }}$ and $1 / 100^{\text {th }}$ with DMS. Antibacterial activity against Bacillus subtilis, Pseudomonas aeruginosa, E. coli and Staphylococcus aureus cultures were evaluated by disc diffusion methods on Muller Hinton agar. In our study methanol and chloroform extract recorded better antibacterial activity than ethanol extract at higher dilution. Chloroform and methanol extracts showed more antibacterial activity than ethanol at lower concentration, water extract doesn't exert any activity. The phytochemical analysis of different solvent extracts of plant show considerable change in the nature of chemicals. Chloroform extract reported maximum number of secondary metabolites than remaining solvents.
\end{abstract}

Keywords: Antibacterial; Secondary metabolites; Flavonoid; Phenolic compounds; Phytochemical; Disc diffusion.

\section{Introduction}

Most of rural people even today depend on plants for medicines. In India, $95 \%$ of the traditional system prescriptions of Unani, Ayurveda, Homeopathy and Siddha are plant based chemicals [1]. The plant based chemical compounds are classified into two classes; primary and secondary metabolites based on their chemical, biosynthetic origin and functional groups. Primary metabolites are involved in growth and development and secondary metabolites are involved in defense mechanism against harmful pests and infectious agents. The later class exhibit medicinal properties. Plant derived chemicals such as terpenoids, phenolics, alkaloids, flavonoids, glycosides, diterpenes, triterpenes and minor chemicals are having better compatibility with the human body. It is estimated that $30 \%$ of the worldwide sales of drugs is based on plant products [2]. The increasing antibiotic resistant pathogens and failure of many chemotherapeutics has led the screening of medicinal plants for their antimicrobial activity [3]. Ruta graveolens $\mathrm{L}$. is an aromatic shrub belongs to family rutaceae and is commonly known as rue, cultivated as ornamental and medicinal herb in gardens. The plant extract is used to treat inflammation [4] and ulcers [5]. This plant extract exerts cytotoxic, antihypotensive [6], antibacterial [7], antihelminthic and phytotoxical [8] properties. Plant extracts are also used in the treatment of reproductive disorders [9]. Decoction of ruta graveolens is used to promote menstruation. The plant contains various volatile compounds and oils [10,11] (Figure 1).

In Ethiopia, the majority of peoples that lives in rural areas and the poor people in urban areas rely mainly on traditional medicines to meet their primary health care needs. Even if their culture and attitude contributed to their usage of traditional medicine, they have no scientifically proved know how. As a result, most of the people may get exposed to unnecessary health problem due to the unfortunate custom of the traditional medicinal plants. In Ethiopia vast knowledge on the traditional uses of medicinal plants is not fully documented and most of the knowledge is conveyed from one generation to the other through words of mouth. The danger of losing valuable information is thus high considering the increasing cultural change, mobility and displacement of communities due to several factors. Moreover, traditional healers have passed on their knowledge only to the members of their own families.
Fresh leaves used to relieve headache. In homeopathy, this plant is used for the treatment of muscular pain, injuries, sprains, eye strain, joint and bone pain, arthritis, rheumatism, toothache, tennis elbow, back pain and headache. The current study was conducted for phytochemical analysis and antimicrobial activity of different solvent extracts of Ruta graveolens.

\section{Materials and Methods}

\section{Sampling site and study area}

The sampling site was Mekelle town $783 \mathrm{~km}$ north of Addis Ababa. Evaluation of the antimicrobial activities of the plant extracts and phytochemical constituency was carried out in organic Laboratory, Department of chemistry, College of Natural and computational science, Mekelle University. Plant material extraction of the candidate traditional medicinal plants was conducted in Chemistry Laboratory, College of Natural and computational Science, and Mekelle University.

\section{Collection and identification of plant materials}

Plants or plant parts used in folklore medicine were collected from different areas of Mekelle Zone; particularly from Kuha sub cites wild places. But plants selected from Mekelle town were purchased from the market. Based on the ethno medicinal survey information obtained from local inhabitants 'Tena Adam' (Ruta graveolens). Each specimen was labeled, numbered, annotated with the date of collection, the locality and their medicinal uses and their approximate dosages of administration were recorded. The specimens were identified at Mekelle University by experienced plant taxonomist.

*Corresponding author: Teklit Gebregiorgis Amabye, Department of Chemistry, College of Natural and Computational Science, Mekelle University, Mekelle, Tigray, Ethiopia, Tel: +251945523645; E-mail: teklitgeb@gmail.com

Received October 31, 2015; Accepted November 03, 2015; Published November 05, 2015

Citation: Amabye TG, Shalkh TM (2015) Phytochemical Screening and Evaluation of Antibacterial Activity of Ruta graveolens L. - A Medicinal Plant Grown around Mekelle,Tigray, Ethiopia. Nat Prod Chem Res 3: 195. doi:10.4172/23296836.1000195

Copyright: ( $) 2015$ Amabye TG, et al. This is an open-access article distributed under the terms of the Creative Commons Attribution License, which permits unrestricted use, distribution, and reproduction in any medium, provided the original author and source are credited. 


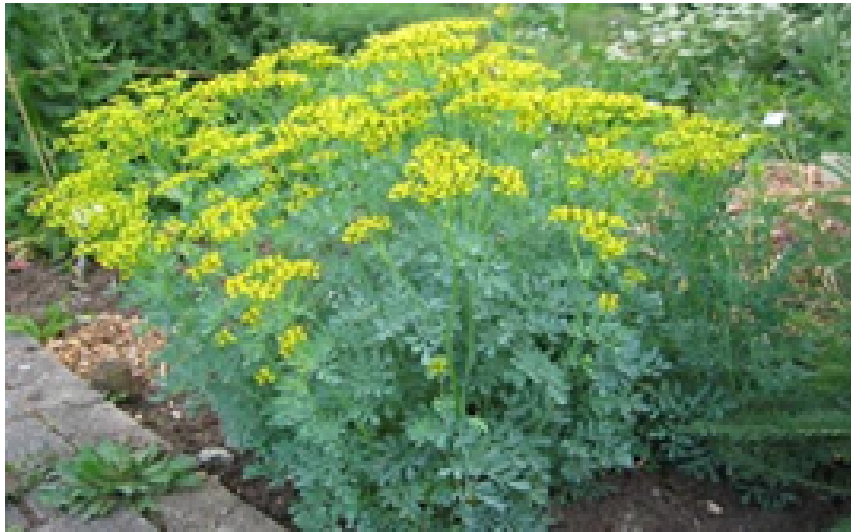

Figure 1: Leaves of Ruta graveolens $\mathrm{L}$

\section{Plant material extraction and antibacterial test}

The fresh leaves were collected in September 2015 and leaves were shade dried at room temperature $\left(25^{\circ} \mathrm{C}\right)$ for 10 days. The dried leaves were powdered and stored in air tight containers. 5 grams of powdered leaves were taken into each round bottom flask and extracted with 25 $\mathrm{ml}$ different solvents, ethanol, methanol, chloroform and distilled water through a flash evaporator for 24 hours. The solution was filtered using a Whatman filter paper. The extract was evaporated at $40^{\circ} \mathrm{C}$. The dried crude extract was dissolved in dimethyl sulfoxide (DMSO). $50 \mathrm{mg} / \mathrm{ml}$ extract was prepared and used for further analysis. Crude solutions were further diluted to $1 / 10^{\text {th }}$ and $1 / 100^{\text {th }}$ with DMS. Antibacterial activity against E. coli, Bacillus subtilis, Staphylococcus aureus and Pseudomonas aeruginosa, cultures were evaluated by disc diffusion methods on Muller Hinton agar. The sterilized media poured up to $3 / 4^{\text {th }}$ of petri dish and bacterial cultures were spread uniformly. The paper discs impregnated with each extract were placed on the inoculated agar plates and incubated for 24 hours at $37^{\circ} \mathrm{C}$. The inhibition zones were measured in $\mathrm{cm}$.

\section{Phytochemical analysis}

For phenol test $5 \mathrm{mg}$ of leaf extract was treated with $2 \%$ ferric chloride, for glycosides $2 \mathrm{ml}$ of glacial acetic acid and 2 drops of $2 \%$ ferric chloride, for triterpenoids $5 \mathrm{mg}$ of the dry leaf extract was treated with $2 \mathrm{ml}$ of chloroform, $1 \mathrm{ml}$ of acetic anhydride and $1 \mathrm{ml}$ of concentrated sulphuric acid. Phenolic compounds were tested by $3 \%$ lead acetate; glycolipids by glacial acetic acid and ferric chloride, steroids were tested by chloroform, saponins by distilled water, and flavonoids by sodium hydroxide and tannins by the acetic anhydride solution (Table 2).

\section{Gas chromatography-mass spectrometry (GC-MS) analysis}

The chemical analysis of the essential oils was carried out using GC-MS (Agilent $6890 \mathrm{~N}$ gas chromatograph, Palo Alto, USA). The chromatographic conditions were as follows: column oven program; $60^{\circ} \mathrm{C}$ ( $1 \mathrm{~min}$, isothermal) to $246^{\circ} \mathrm{C}\left(3 \mathrm{~min}\right.$, isothermal) at $3^{\circ} \mathrm{C} / \mathrm{min}$, the injector and detector temperatures were $250^{\circ} \mathrm{C}$ and $300^{\circ} \mathrm{C}$, respectively. Helium was the carrier gas (flow rate $0.90 \mathrm{~mL} / \mathrm{min}$ ), and the ionization voltage was maintained at $70 \mathrm{eV}$. An HP-5 MS capillary column (30 $\mathrm{m} \times 0.25 \mathrm{~mm}$ i.d., $0.25 \mu \mathrm{m}$ film thicknesses) was used. A hydrocarbon mixture of $n$-alkanes $\left(\mathrm{C}_{8}-\mathrm{C}_{20}\right)$ was analyzed separately by GC-MS under the same chromatographic conditions using the same HP-5 column. Kovats Retention Indexes (KRIs) were calculated by injection of a series of $n$-alkanes $\left(\mathrm{C}_{8}-\mathrm{C}_{20}\right)$ in the same column and conditions as above for gas chromatography analyses.
The identification of the oil constituents was based on a computer search using the library of mass spectral data (http://www.massbank. jp) and a comparison of the calculated KRIs with those of the available authentic standards and literature data was drawn.

\section{Results and Discussion}

The biological activity of the plant depends on many factors like, plant part, geographical source, soil conditions, and time of the harvest, moisture and post-harvest process methods. For example, high temperature during tissue grinding may denature certain chemical constituents. Different concentrations of solvent or different solvents alone or combinations are used for the maximum recovery of bioactive compounds, because different plants constitute different compositions of active compounds. Different extraction protocols are followed in herbal medicine preparation, ethanol-water mixture extraction protocols are used in majority of herbal medicine industries [12]. The antimicrobial properties of plant extracts have been treated as new classes of antibiotics [13]. Ruta graveolens plant extracts showed more effect on gram positive bacteria than gram negative bacteria [14], antibacterial activity reported on Staphylococcus aureus [15], Bacillus subtilis [16]. Guarrera et al. reported anti parasitic activity. Both hydro and hydroalcholic (ethanol 70\%) extracts of this plant shows no antibacterial effect on main human pathogens $[17,18]$.

In vitro antibacterial efficiency of different extracts $R$. graveolens were assayed based on their zone of inhibition. Chloroform extract of $R$. graveolens showed antimicrobial activity on both Gram positive and Gram negative bacteria. Chloroform extract observed maximum activity against $E$ coli with $2.4 \mathrm{~cm}$ zone of inhibition and minimum against Pseudomonas aeruginosa with $0.8 \mathrm{~cm}$ zone of inhibition. And moderate against $B$. subtilis and $S$. aureus with zone of inhibition of $1.8 \mathrm{~cm}$ and $1.4 \mathrm{~cm}$ respectively. Antibacterial activity decreased for $1 / 10^{\text {th }}$ and $1 / 100^{\text {th }}$ dilution. Increasing dilutions observed maximum decreased activity against $E$ coli, and moderate against $B$. subtilis and $P$. aeruginosa, and no variation in the activity against $S$. aureus. This study indicated that, at lower concentrations of chloroform extract showed maximum activity on $S$. aureus and minimum activity against $P$. aeruginosa. As the concentration increased its activity increased maximum against $E$. coli. Methanol extract exert similar antibacterial activity on E. coli, B. subtilis with $1.7 \mathrm{~cm}$ of zone of inhibition and lower activity on $S$. aureus and $P$. aeruginosa with $1.3 \mathrm{~cm}$ and $1.1 \mathrm{~cm}$ of zone of inhibition respectively. $1 / 10^{\text {th }}$ dilution recorded reduced activity on E. coli, B. subtilis and S. aureus, but retained same activity against $P$. aeruginosa culture. $1 / 100^{\text {th }}$ dilution recorded maximum decreased activity against $E$. coli and narrow decreased activity against $B$. subtilis and no change against $S$. aureus and $P$. aeruginosa. This indicates that at lower concentration methanol extract showed maximum activity against $S$. aureus and $P$. aeruginosa and minimum on remaining organisms and vice versa at higher concentrations. Ethanol extract reported maximum antibacterial activity against $E$. coli with $1.9 \mathrm{~cm}$ zone of inhibition and same type of antibacterial activity against remaining organisms with $1.5 \mathrm{~cm}$ of zone of inhibition. Antibacterial activity against all organisms gradually decreased for $1 / 10^{\text {th }}$ dilution. $1 / 100^{\text {th }}$ dilutions were observed no zone of inhibition for $S$. aureus and $P$. aeruginosa. An aqueous extract of the plant was not shown zone of inhibition against any of four organisms. It indicated that aqueous extraction doesn't contain the secondary metabolites of antimicrobial activity. Methanol extract reported faster wound healing property in experimental rats [19]. Methanol extracts were also reported for their antifungal property [20]. Harish Kumar et al. reported maximum zone of inhibition for methanol extracts against K. pneumonia and S. aureus [21]. An ethanol extract of Ruta graveolens has more antifungal activity 


\begin{tabular}{|l|c|c|c|}
\hline \multirow{2}{*}{ Organism } & \multicolumn{3}{c|}{ Zone of inhibition in cm } \\
\cline { 2 - 4 } & Crude Extract & $\mathbf{1 / 1 0 ^ { \text { th } }}$ Dilution & $\mathbf{1 / 1 0 0 ^ { \text { th } }}$ Dilution \\
\hline E. coli & 2.4 & 1.6 & 0.6 \\
\hline Bacillus subtilis & 1.8 & 1.4 & 0.9 \\
\hline Staphylococcus aureus & 1.4 & 1.3 & 1.3 \\
\hline Pseudomonas aeruginosa & 0.8 & 0.7 & 0.4 \\
\hline
\end{tabular}

Table 1: Zone of inhibition of chloroform extract.

\begin{tabular}{|l|c|c|c|}
\hline \multirow{2}{*}{ Organism } & \multicolumn{3}{c|}{ Zone of inhibition in cm } \\
\cline { 2 - 4 } & Crude Extract & $\mathbf{1 / 1 0 ^ { \text { th } }}$ Dilution & $\mathbf{1 / 1 0 0 ^ { \text { th } }}$ Dilution \\
\hline E. coli & 1.7 & 1.31 & 0.7 \\
\hline Bacillus subtilis & 1.7 & 0.8 & 0.7 \\
\hline Staphylococcus aureus & 1.3 & 1.0 & 1.2 \\
\hline Pseudomonas aeruginosa & 1.1 & 1.2 & 1.3 \\
\hline
\end{tabular}

Table 2: Zone of inhibition of methanol extract.

than methanol [20]. Olia et al. observed the antibacterial effect against Pseudomonas aeruginosa for hydroalcholic extract of the plant [22] (Table 3).

Crude aqueous or alcoholic extracts are generally used in the initial screening of plants for antimicrobial activities [23]. The current phytochemical analysis of different solvent extracts of Ruta graveolens observed considerable change in the nature of chemical composition. The chloroform extract constitutes more class of chemicals such as phenols, glycosides, phenolic compounds and cardiac glycolipids. Methanol extract constitutes glycosides, triterpenoids and cardiac glycolipids, ethanol is general extraction solvent for many plant extracts, constitute glycosides, phenolic compounds and cardiac glycolipids, water extract contains phenolic compounds, cardiac glycolipids and steroids. Chemicals like, alkaloids, coumarins, terpenoids, volatile substances, furoquinolines and flavonoids have been isolated from Ruta graveolens [24]. Presence of saponin, tannins and glycosides are reported by Hashemi et al. [25]. Volatile oils contain high content of aliphatic acids, ketones and alcohols [26]. Flavonoids such as rutin and quercetin isolated from the leaves of $R$. graveolens [27]. The phenolic compounds, alkaloids and terpenoides extracted from ruta graveolens reported antimicrobial activity against Staphylococcus aureus and Bacillus subtilis [16]. Furanocoumarins of this plant reported as potent antioxidants $[28,29]$. Flavonoids are one of the widespread groups of natural compounds and the most important natural phenolics present in $R$. graveolens they possess a broad spectrum free radical scavenging properties [30,31] (Table 4).

Crude extracts of all methods show good results, but on higher dilution methanol extract recorded maximum zone of inhibition against all four organisms. Chloroform extract was also recorded considerable antibacterial activity for all four organisms. The crude ethanol extract was recorded better antibacterial activity for all organisms, but its antibacterial effect decreased with increased dilution. $1 / 100^{\text {th }}$ dilution of ethanol extract had no antibacterial effect on $S$. aureus and $P$. aeruginosa. In our study methanol and chloroform extract recorded better antibacterial activity than ethanol extract at higher dilution.

The hydro distillation of fresh leaves and stems gave colourful oil yields of $0.30 \%$ and $0.10 \%$ respectively. It seemed that the leaves were richer in essential oils than the stems.

The EOs composition was tested two weeks after hydro distillation. The general chemical profiles of the tested oils, the percentage content of the individual components, the retention indices and the chemical class distribution of the oil compounds are summarized in Table 5.

In all tested oils, 15 components were identified which represented
98.71-98.68\% of the total detected constituents. The major components of the leaves were 2-nonanone (38.66\%) and 2-undecanone (27.34\%), followed by 2-nonanol (12.25\%), 2-octyl acetate (7.71\%) and 2-undecanol (3.25\%). Other components were present in amounts less than 3\% (Table 1). In particular, ketones were the most abundant compound group (69.77\%).

In the stem oils, 2 -undecanone (40.28\%) was the major component followed by 2 -nonanone (34.99\%), 2-nonyl acetate $(9.68 \%)$ and 2-nonanol (3.69\%). Similarly to leaves, ketone groups were also the

\begin{tabular}{|c|c|c|c|}
\hline \multirow[t]{2}{*}{ Organism } & \multirow[t]{2}{*}{ Crude extract } & \multicolumn{2}{|c|}{ Zone of inhibition in $\mathrm{cm}$} \\
\hline & & $1 / 10^{\text {th }}$ dilution & $1 / 100^{\text {th }}$ Dilution \\
\hline E. coli & 1.9 & 1.1 & 1 \\
\hline Bacillus subtilis & 1.5 & 0.9 & 0.8 \\
\hline Staphylococcus aureus & 1.5 & 1.2 & 0 \\
\hline Pseudomonas aeruginosa & 1.6 & 0.7 & 0 \\
\hline
\end{tabular}

Table 3: Zone of inhibition of ethanol extract.

\begin{tabular}{|l|c|c|c|c|}
\hline \multicolumn{1}{|c|}{$\begin{array}{c}\text { Chemicals } \\
\text { present }\end{array}$} & $\begin{array}{c}\text { Chloroform } \\
\text { extract }\end{array}$ & $\begin{array}{c}\text { Methanol } \\
\text { extract }\end{array}$ & Ethanol extract & $\begin{array}{c}\text { Distilled } \\
\text { water }\end{array}$ \\
\hline Phenols & + & - & - & - \\
\hline Glycosides & + & + & + & - \\
\hline Triterpenoids & - & + & - & - \\
\hline Phenolic & + & - & + & + \\
\hline compounds & & + & + & + \\
\hline Glycolipids & + & + & - & - \\
\hline Flavonoids & - & - & - & - \\
\hline Saponins & - & - & - & - \\
\hline Tannins & - & - & - & - \\
\hline Ferric chloride & - & - & - & + \\
\hline Steroids & - & - & & \\
\hline
\end{tabular}

Table 4: Phytochemical analysis of Ruta graveolens. Key: +: Presence; -: Absence.

\begin{tabular}{|l|l|l|l|}
\hline No & Compound & $\begin{array}{l}\text { Retention indices } \\
\text { HP-20M }\end{array}$ & Fresh leaves \\
\hline 1 & Myrcene & 1161 & 0.3 \\
\hline 2 & Limonene & 1196 & 2.48 \\
\hline 3 & Terpinolene & 1286 & $\mathrm{Tr}$ \\
\hline & Monoterpene hydrocarbons & & 2.78 \\
\hline 4 & 2-Nonanone & 1392 & 38.66 \\
\hline 5 & 2-Decanone & 1482 & 1.86 \\
\hline 6 & 2-Undecanone & 1681 & 27.34 \\
\hline 7 & 2-Dodecanone & 1692 & 0.85 \\
\hline 8 & 2-Tridecanone & 1705 & 0.79 \\
\hline 9 & 2-Tridecanone & 1793 & 0.27 \\
\hline & Ketones & & 69.77 \\
\hline 10 & 2-Nonyl acetate & 1425 & 2.02 \\
\hline 11 & 2-Docyl acetate & 1455 & 0.24 \\
\hline 12 & 2-Octyl acetate & 1497 & 7.71 \\
\hline & Esters & & 9.97 \\
\hline 13 & 2-Nonanol & 1499 & 12.25 \\
\hline 14 & 2-Undecanol & 1717 & 3.25 \\
\hline 15 & Alcohols & & 15.5 \\
\hline & Naphtalene & & 0.63 \\
\hline & Aromatic products & & 0.63 \\
\hline & Total & & 98.71 \\
\hline & Essental & & \\
\hline
\end{tabular}

Table 5: Essential oils chemical composition of Ruta graveolens from mekelle Tigray Ethiopia represented in \%. 
Citation: Amabye TG, Shalkh TM (2015) Phytochemical Screening and Evaluation of Antibacterial Activity of Ruta graveolens L. - A Medicinal Plant Grown around Mekelle,Tigray, Ethiopia. Nat Prod Chem Res 3: 195. doi:10.4172/2329-6836.1000195

most abundant chemical groups. It is evident that there are many qualitative similarities between the tested oils in spite of the fact that the amounts of some corresponding compounds are different.

Comparison of the tested oils with the data [19-22] that have been published on the oil composition of other samples of Ruta graveolens L. showed that there are some quantitative and qualitative differences. These chemical differences can be most probably explained by the existence of different chemotypes.

\section{Conclusion}

This study is the first to report on the essential oil composition of Ruta graveolens from Ethiopia.

The medicinal plants are the rich source of various bioactive compounds that make traditional medicine to combat and cure various ailments. The medicinal properties are due to the high steroids, flavonoids, phenols, tannins, terpenoids and saponins. Further investigations are required for specific activity evaluation and downstream processing technology.

\section{Acknowledgement}

The Author expresses thanks to the chairman of the department of chemistry and biology and Mekelle tissue culture and Ethiopian Agricultural research institute for extending his cooperation for carrying this study.

\section{References}

1. Satyavati GV, Gupta AK (1987) Medicinal Plants of India eds. Indian Council of Medical Research, New Delhi.

2. Patwardhan B, Vaidya ADB, Chorghade M (2004) Ayurveda and natural products drug discovery. Curr Sci 86: 789-799.

3. Colombo ML, Bosisio E (1996) Pharmacological activities of Chelidonium majus L. (Papaveraceae). Pharmacol Res 33: 127-134.

4. Ratheesh M, Shyni GL, Sindhu G, Helen A (2009) Protective Effects of Isolated Polyphenolic and Alkaloid Fractions of Ruta graveolens L. on Acute and Chronic Models of Inflammation. Inflammation 9: 4983-4986.

5. Sangeeta R, Harjeet S, Dalal PK, SrivastavaJS, Asthana OP (2006) Randomized controlled trial of standardized Bacopa monniera extract in ageassociated memory impairment. Indian J Psychiatry 48: 238-242.

6. Chiu KW, Fung AY (1997) The cardiovascular effects of green beans (Phaseolus aureus), common rue (Ruta graveolens), and kelp (Laminaria japonica) in rats. Gen Pharmacol 29: 859-862.

7. FarahH, Tarik MC, Yosr Z, Riadh K, Amina A, et al. (2013) Chemical composition and antimicrobial activity of the essential oils from four Ruta species growing in Algeria. Food Chemistry 141: 253-258.

8. Asgarpanah J, Khoshkam R (2012) Phytochemistry and pharmacological properties of Ruta graveolens L. Journal of Medicinal Plants Research 6: 3942-3949.

9. Browner $\mathrm{CH}$ (1985) Plants used for reproductive health in Oaxaca, Mexico. Econ Bot 39: 482-504.

10. Kostova I, Ivanova A, Mikhova B, Klaiber I (1999) Alkaloids and coumarins from Ruta graveolens. Monatsh Chem 130: 703-707.

11. Masho H, Unnithan CR, Mehari M, Desta G, Reddy DN, et al. (2015) Extraction, isolation and chemical composition of the essential oil of Rutagraveolens $L$ of mekelle, northern Ethiopia. Inter J of Pharmacotherapy 5: 05-07.

12. Ganora L (2008) Herbal Constituents: Foundations of Phytochemistry. Herbal Chem Press, Louisville, 38-52.

13. Ali NA, Julich WD, Kusnick C, Lindequist $U$ (2001) Screening of Yemen medicinal plants for antibacterial and cytotoxic activities. J Ethnopharmacol 74: 173-179.

14. Alzoreky NS, Nakahara K (2003) Antibacterial activity of extracts from some edible plants commonly consumed in Asia. International Journal of Food Microbiology. 80: 223-230.

15. Ojala T, Remes S, Haansuu P, Vuorela H, Hiltunen R, et al. (2000) Antimicrobia activity of some coumarin containing herbal plants growing in Finland. Journal of Ethnopharmacology 73: 299-305.
6. Al-Bakri AG, Afifi FU (2007) Evaluation of antimicrobial activity of selected plant extracts by rapid XTT colorimetry and bacterial enumeration. J Microbio Methods 68:19-25

17. Guarrera PM (1999) Traditional antihelmintic, antiparasitic and repellent uses of plants in Central Italy. Journal of Ethnopharmacology 68: 183-192.

18. Ahmadi M, Honarmand H, Falah-Delavar S, Saeidinia A (2012) Study on antibacterial effect of Ruta graveolens extracts on pathogenic bacteria. Annals of Biological Research 3: 4542-4545.

19. Hayder BS, Mazin HO, Ibrahim SA, Asawer A, Enas AK, et al. (2014) The Wound Healing Activity of (Rue) Ruta graveolens L. Methanolic Extract in Rats. Int J Pharm Sci Rev Res 29: 263-266.

20. Issa GA,Seyed MH (2012) Effect of Aquatic, Methanolic and Ethanoliclic Extracts of Ruta graveolens on Some Mycotoxigenic Fungi. American-Eurasian J Agric \& Environ Sci 12: 729-732.

21. Harish Kumar K, Shanmugavadivu M, Ranjithkumar R, Selvam K (2014) Antibacterial Activity of Different Solvent Extracts of Medicinal Plant: Ruta Graveolens $L$. International Journal of Biosciences and Nanosciences 1: 9-11.

22. Olia P, Saderi H, Tabatabaeijejad A, Naseri M (2004) Researches on medical plants of Iran. 20: 171-180.

23. Cowan MM (1999) Plant products as antimicrobial agents. Clin Microbiol Rev 12: $564-582$

24. Kuzovkina I, Al-terman I, Schneider B (2004) Specific accumulation and revised structures of acridone alkaloid glucosides in the tips of transformed roots of Rutagraveolens. Phytochemistry 65: 1095-1100.

25. Hashemi KSM, Sadeghpour HM, Gholampour AI, Mirzaei JH (2011) Survey the antifungal effect of root ethanolic extract of Ruta graveolens on Saprolegnia. Spp Int Con Biotech Environ Manage 18: 19-23.

26. Ivanovaa A, Kostovaa I, Navasb HR, Villegasc J (2003) Volatile Components of Some Rutaceae Species. ZNaturforsch 59: 169-173.

27. Pathak S, Multani AS, Banerji $P$ (2003) Ruta 6 selectively induces cell death in brain cancer cells but proliferation in normal peripheral blood lymphocytes: A novel treatment for human brain cancer. Int J Oncol 23: 975-982.

28. Karagozler A, Erdag B, Emek Y, Uygun D (2008) Antioxidant activity and proline content of leaf extracts from Dorystoechas hastate. Food Chem 111: 400-47.

29. Piao X, Park I, Baek S, Kim H, Park M, et al. (2004) Antioxidative activity of Furanocoumarins isolated from Angelicae dahuricae. J Ethnopharmacol 93 243-246.

30. Liu X, Zhao M, Wang J, Yang B, Jiang Y (2008) Antioxidant activity of methanolic extract of emblica fruit (Phyllanthusemblica L.) from six regions in China. J Food Comp Ana 21: 219-228.

31. Hollman PCH, Katan MB (1999) Dietary flavonoids: Intake, Health effects and bioavailability. Food ChemToxicol 37: 937-942. 